\title{
UM DIREITO PENAL DESAFIADO PELO DESENVOLVIMENTO TECNOLÓGICO: ALGUNS EXEMPLOS A PARTIR DAS NEUROCIÊNCIAS E DA INTELIGÊNCIA ARTIFICIAL
}

\begin{abstract}
Susana Aires de Sousa
Universidade de Coimbra, Instituto Jurídico da Faculdade de Direito da Universidade de Coimbra Professora auxiliar, com nomeação definitiva, da Faculdade de Direito da Universidade de Coimbra, Investigadora do Instituto Jurídico da Faculdade de Direito da Universidade de Coimbra, Senior Fellow do Carol and Lawrence Zicklin Center for Business Ethics Research, da Wharton School da Universidade de Pensilvânia (EUA) Doutora em Ciências Jurídico-Criminais pela Universidade de Coimbra Mestre em Ciências Jurídico-Criminais pela Universidade de Coimbra https://apps.uc.pt/mypagelfaculty/susanaas susanaas@fd.uc.pt
\end{abstract}

\section{RESUMO}

$\mathrm{O}$ avanço do conhecimento científico e da tecnologia tem colocado sobre tensão algumas categorias e princípios que conformam o direito e o processo penal. Este texto procura elencar alguns desafios lançados pelo desenvolvimento das neurociências e das técnicas de inteligência artificial no contexto da teoria do crime e da teoria do processo. Num primeiro momento, atende-se aos conceitos de causalidade e culpabilidade; num segundo momento, centrado sobre a teoria do processo, abordam-se novas formas probatórias e de avaliação de risco em processo penal, evidenciando-se a necessidade de estabelecer critérios de admissibilidade deste conhecimento novo, qualificado como científico. Conclui-se com uma advertência, implicitamente contida em toda esta problemática, sobre a silenciosa transformação do direito penal do facto num possível direito penal do agente "diagnosticado" como perigoso ou de "elevado risco".

\section{SUMÁRIO}

1. Introdução: um direito penal desafiado pelo desenvolvimento tecnológico 2 . Na teoria do crime 2.1 A imputação de resultados desvaliosos: Crime sem causa? Crime sem culpabilidade? 2.2 A IA e a categoria da causalidade (black box problem) 2.3 As neurociências e a categoria da culpabilidade 3. Na teoria do processo penal 3.1 As neurociências e a descoberta da verdade material 3.2 A IA como instrumento de previsão e de avaliação de risco 3.3 Questáo comum: o problema da admissibilidade de nova prova de natureza científica em processo penal 4. Nota conclusiva

\section{Introdução: um direito penal desafiado pelo desenvolvimento tecnológico}

Em março de 2018, Elaine Herzberg foi mortalmente atropelada, em Tempe, no Arizona 
(EUA) por um carro autónomo. Elaine empurrava uma bicicleta, enquanto atravessava uma estrada em local não adequado para pedestres, quando sofreu o embate de um carro autónomo em fase de testes. A tecnologia existente no veículo revelou que a intervenção humana da pessoa que se encontrava dentro do veículo se dá menos de um secundo depois do impacto. A informação gravada mostra ainda que o sistema detetou Herzberg seis secundos antes da colisão, tendo tido dificuldade, num primeiro momento, em identificar e reconhecer o obstáculo, qualificando-o como veículo e, seguidamente, como bicicleta. Em 2013, Eric Loomis foi detido e acusado da prática de vários atos com relevância criminal (detenção de arma proibida, condução de carro roubado, não cumprimento de ordem policial e fuga com tiroteio). Em negociação com o Ministério Público, Loomis dá-se como culpado (guilty plea). Na determinação da sentença, o juiz socorre-se de um sistema algorítmico de inteligência artificial (COMPAS, Correctional Offender Management Profiling for Alternative Sanctions ), produzido por uma empresa privada, para avaliar o risco de reincidência de Loomis. Atendendo ao registo criminal de Loomis e com base no resultado do algoritmo, que determinou um risco elevado para aquele concreto agente, o juiz aplicou uma pena de seis anos de prisão efetiva.

Terry Harrington foi condenado, em 1978, pelo homicídio de um polícia em pena de prisão perpétua. Durante o julgamento sempre se afirmou inocente, indicando estar a assistir a um concerto quando o crime foi cometido. Em 1997, interpóe recurso, com base no desenvolvimento tecnológico e científico de uma técnica designada brain fingerprint, desenvolvida por Lawrence Farwell, nos termos da qual, através de um exame eletroencefalográfico e da medição da resposta elétrica cerebral a determinados estímulos (potenciais evocados positivos, em particular a onda $\mathrm{P} 300^{1}$ ), é possível aferir a impressão mental de acontecimentos vividos ou experimentados. O resultado do exame foi "ausência de informação" perante as cenas do crime e "informação presente" quanto ao concerto. Muito embora esta nova informação não fosse admitida como prova em tribunal, influenciou a decisão de repetir do julgamento. Provada a inconsistência da acusação e das provas apresentadas contra Harrington, ele vem a ser absolvido, depois de cumprir 24 anos na prisão.

Estes são apenas alguns exemplos que permitem mostrar como a evolução científica e tecnológica tem vindo a desafiar a ciência penal em sentido amplo. Desde já se antecipa o propósito muito limitado das reflexóes que se seguem. Mais do que um texto analítico ou crítico, este texto assume-se essencialmente informativo, se bem que com uma secundária finalidade: a de causar alguma inquietação, eventualmente algum desconforto ou perturbaçáo, sempre convocando o património adquirido de princípios e garantias fundamentais que conformam o direito e o processo penal dos dias de hoje.

Deste modo, assumindo-se como um texto informativo, em alguns momentos mesmo descritivo, dele não se espere qualquer solução jurídica. Através dele, num propósito que desde o início se assume como curto ou pouco ambicioso, pretende-se elencar, de forma mais ou menos clara, alguns dos desafios que o desenvolvimento do conhecimento cien-

\footnotetext{
Uma descrição mais desenvolvida sobre o exame neurológico baseado na medição da onda P 300, SusANA Aires de Sousa, "Neurociências e processo penal: verdade ex machina», Estudos em homenagem ao Prof. Doutor Manuel da Costa Andrade, Vol. II, Instituto Jurídico da Faculdade de Direito da Universidade de Coimbra, Coimbra, 2017, p. 890 e ss.
} 
tífico e das potencialidades tecnológicas têm colocado ao direito e ao processo penal. Percorrendo a literatura e sem prejuízo de num ou noutro ponto se assumir uma perspetiva crítica, pretende-se sobretudo narrar e apontar alguns exemplos de como as possibilidades tecnológicas, potenciadas pelo avanço do conhecimento científico, têm colocado sobre pressão algumas categorias e princípios do direito penal até aqui tomados por assentes e adquiridos.

Em seguida, procurar-se-á indicar alguns desses exemplos, ainda que de modo fragmentário, como forma de sublinhar este conflito e tensão existentes entre a teoria do crime e do processo, de um lado, e as novas tecnologias (de outro), em especial aquelas que têm vido a ser exploradas pelas neurociências e pela inteligência artificial (IA).

\section{Na teoria do crime}

\subsection{A imputaçáo de resultados desvaliosos: Crime sem causa? Crime sem culpabilidade?}

A responsabilidade penal depende da afirmação de um juízo de imputação: a atribuição de um evento, tido como socialmente desvalioso - por violador de um bem jurídico - a uma conduta humana. $\mathrm{Na}$ concretização desse juízo, o direito penal socorre-se de categorias de que são exemplo, no plano da imputaçáo objetiva, a causalidade e, no plano da censurabilidade do agente, a categoria de culpabilidade. Causalidade e culpabilidade constituem o suporte fundamental do juízo objetivo e subjetivo de imputaçáo de um facto a um agente e, consequentemente, de atribuição de responsabilidade penal.

Embora cumprindo distintas funçóes, causa e culpabilidade partilham, com frequência, o mesmo cenário problemático, designadamente no contexto dos problemas que em seguida seráo descritos e expostos ligados ao desenvolvimento tecnológico. Em primeiro lugar, há uma certa proximidade "genética" entre estas categorias no cumprimento da função de atribuição de responsabilidade: a palavra grega aitia ( $\mathbf{\alpha} \mid \mathrm{TI} \mathbf{\alpha})$, termo de cariz normativo que originalmente significava culpa, viria mais tarde a ser traduzida por causa ${ }^{2}$. Na base desta proximidade está a possibilidade de o conhecimento experimental dos acontecimentos permitir um juízo de previsibilidade que permite ao agente a possibilidade de os dominar, de os comandar ${ }^{3}$, atuando e escolhendo em conformidade com os valores protegidos pela ordem jurídica. Em segundo lugar, ambas as categorias - causa e culpabilidade - se encontram no centro do debate entre determinismo / indeterminismo: da natureza, no caso

\footnotetext{
2 Como sublinha, Hans Kelsen, Teoria Pura do Direito, op. cit., p. 99 e "Causality and Imputation", in: What is Justice? Justice, Law and Politics in the Mirror of Science, New Jersey: The Lawbook Exchange,

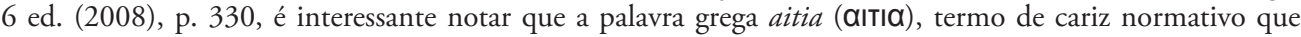
originalmente significava culpa, viesse a ser traduzida por causa: "a causa é a culpa pelo efeito, a causa é responsável pelo efeito e o efeito é imputado à causa da mesma forma que a pena o é ao acto ilícito”. Segundo Ferrater Mota, tal impele à conclusão de que, ao passar do campo normativo para o campo filosófico, se evidencia que não há apenas uma imputação a alguém ou a algo, mas que o evento se dá segundo certa lei, ou que a regularidade do acontecer é válida para todos os acontecimentos da mesma espécie, ou que a transmissão de propriedades de uma coisa a outra se faz segundo um certo princípio ou, simultaneamente, todas estas coisas, apud Guillermo Julio Fierro, Causalidad e Imputación, Buenos Aires: Astrea, 2002, p. 3.

3 Neste sentido, Manfred Maiwald, Kausalität und Strafrecht, Verlag Otto Schwartz, 1980, p. 82.
} 
do conceito de causa, e da atuação humana, no que se refere ao conceito de culpabilidade. E, por fim, de modo mais geral, ambas as categorias, reproduzem conceitos transversais que tocam diversas áreas do conhecimento, desde o direito à ciência e à filosofia ${ }^{4}$. Esta sua marcada transversalidade potencia que ambas sejam categorias interpeladas - até desafiadas no cumprimento da sua função jurídico-penal - pela exponencial evolução do conhecimento científico e tecnológico dos últimos anos.

\subsection{A IA e a categoria da causalidade (black box problem) ${ }^{5}$}

O esquema da atribuição da responsabilidade penal por um resultado material pressupóe uma conduta humana, típica, que dá causa a um acontecimento tido como desvalioso pelo ordenamento jurídico-penal. No plano objetivo, o estabelecimento de uma relação de causalidade entre um resultado desvalioso e uma conduta humana mostra-se agora dificultado quando entre ambos - conduta e resultado - se interponha uma máquina "inteligente" (por exemplo, um carro autónomo), com alguma liberdade em determinadas opçóes. Por máquina "inteligente" referimo-nos a sistemas computacionais complexos, capazes de aprender (machine learning), não se limitando a calcular a melhor opção de entre aquelas que integram os dados que lhe foram introduzidos; isto é, a máquina não se limita a fazer uma análise em si mesmo inacessível ou muito difícil para o humano (como, por exemplo, optar por uma das inúmeras possibilidades de jogada num jogo de estratégia como o xadrez); antes procura, analisa e compara padróes para formular um juízo $^{6}$. Neste sentido, o algoritmo, alimentado com dados, ajusta-se continuamente, por forma a diminuir o erro e a tomar a sua própria açáo. Esta natureza dinâmica da máquina, determinada não a fazer, mas a aprender, permite-lhe criar o seu próprio modelo. É esta autonomia que se interpóe entre a conduta humana - do programador ou do utilizador da máquina - e o resultado desvalioso, por exemplo a morte por atropelamento ligada à condução automática de um carro autónomo que toma o peão que circula numa bicicleta por um obstáculo.

Em casos em que o sistema é computacionalmente complexo e pré-programado a aprender (por exemplo com o ambiente em que é inserido), a descrição do concreto mecanismo que determinou a resposta dada pela máquina é muitas vezes inacessível ou inexplicável aos próprios programadores, enunciando-se o que na literatura se designa como black box problem. Este problema da "caixa negra" remete para a opacidade e a falta de transparência de alguns modelos mais complexos de inteligência artificial na forma como processam os

\footnotetext{
4 Cf., sobre estes pontos, Susana Aires De Sousa, «Boundaries and connections between law and science: the limits of causality and culpability: (from the perspective of criminal law)», International Journal of Semiotics of Law (submetido para publicaçáo).

5 Desenvolvidamente sobre estes problemas, com adicionais referências bibliográficas, SUSANA AIRES DE SousA, «"Não fui eu, foi a máquina”: teoria do crime, responsabilidade e inteligência artificial», em curso de publicação.

6 Cf. desenvolvidamente sobre este ponto, Yavar Bathaee, «The artificial intelligence black box and failure of intent and causation», Harvard Journal of Law \& Technology, Vol. 31, 2018, p, 898.Veja-se, por exemplo, o programa Alpha Go desenvolvido pela empresa Deep Mind, mais tarde adquirida pela Google, capaz de criar as suas próprias jogadas, qualificadas, aos olhos de um jogador profissional, como criativas.
} 
dados (input) e alcançam um determinado resultado (output). Isto é, o tratamento algorítmico dos dados, segundo uma estrutura não-linear, torna opaco o processo que conduz a determinado resultado, ficando por explicar como tudo aconteceu; ou, em outras palavras, não sendo possível determinar o concreto mecanismo que levou ao resultado. Depressa se assinalaria, nestes casos, a dificuldade de prova do nexo de causalidade entre a conduta e o resultado e, com isso, a atribuição de responsabilidade penal.

Sempre se dirá, da nossa perspetiva, não ser este um problema jurídico inteiramente novo. A questão de saber se a imputação de um resultado exige o conhecimento pormenorizado do concreto mecanismo causal foi já abordado pela jurisprudência e pela literatura penal no passado, sobretudo em casos associados a danos de produtos inovadores ou recentemente introduzidos no mercado ${ }^{7}$, colocando em evidência as dificuldades em provar o nexo de causalidade por impossibilidade de se aceder ao concreto mecanismo causal ${ }^{8}$. Somos assim remetidos para o problema da responsabilidade criminal pelo produto e para as dificuldades em estabelecer o nexo de causalidade quando não haja regras de experiência ou conhecimento adquirido sobre um determinado produto.

Um verdadeiro case study, na abordagem desta problemática, foi o caso Lederspray ${ }^{9}$, no contexto do qual o BGH alemão dá como provado um nexo de causalidade entre o uso de um produto (spray para sapatos e produtos de pele) e as lesóes sofridas pelos consumidores, ainda que náo tenha sido possível ao tribunal descrever o concreto mecanismo causal - ou identificar em concreto qual a substância ou combinação de substâncias - que resultou naquelas lesóes. Com efeito, o tribunal reconheceu que, dos factos provados em audiência, não foi possível determinar, de um ponto de vista científico-natural, qual dos elementos ou combinação de elementos é que conferiu ao produto uma propriedade lesiva da saúde dos consumidores. Porém, "verificou-se de maneira juridicamente correta que algum dos componentes integrantes do produto - ainda que não tenha sido possível determinar com maior pormenor qual deles - foi a causa dos danos, logo já não se mostra necessário, para demonstrar a relação de causalidade, que adicionalmente se comprove por que razáo essas substâncias causaram aqueles danos, e, por conseguinte, qual foi, segundo a análise dos conhecimentos científico-naturais, a causa dos mesmos" ${ }^{10}$.

Esta constitui uma afirmação nuclear em matéria de causalidade, que transformou esta decisão em objeto de análise e de reflexão por parte da literatura penal, indagando-se da adequação da teoria da condição para aferir da causalidade em casos como este. $\mathrm{O}$ tribunal considerou que alguma das substâncias que integravam aquele spray, ou, em alternativa, uma combinação entre elas, foi causa dos danos à saúde dos consumidores, ainda que não haja um conhecimento exato do encadeamento causal entre o fator nocivo e o dano. Esta ligação causal é suportada pelos juízes em ulteriores consideraçóes: de um lado, a existência de uma estreita relação temporal entre o uso do spray e a lesão na saúde;

\footnotetext{
Sobre este problema, desenvolvidamente, Susana Aires de Sousa, A Responsabilidade Criminal Pelo Produto e o Topos Causal em Direito Penal, Coimbra Editora, 2014, p. 51 e ss., p. 315 e ss.

8 Cf. Susana Aires de Sousa, Responsabilidade Criminal Pelo Produto, op. cit., p. 482 e ss.

9 Uma descrição sobre este caso e as decisóes judiciais proferidas pode ver-se em SuSANA AIrEs DE Sousa, A Responsabilidade Criminal pelo Produto..., op. cit., p. 23 e ss. e 253 e ss.

10 Cf. BGHSt 37 (1992), p. 112.
} 
de outro, a ausência de outra explicação causal para aqueles danos ${ }^{11}$. A argumentação do tribunal seria então comparada à imagem da caixa negra utilizada pelo ilusionista (teoria da black-box): controla-se o que entra na caixa e aquilo que dela sai, mas o seu conteúdo permanece desconhecido ${ }^{12}$. Ou seja, sabe-se que o uso do produto está correlacionado com a verificação de determinados danos; pode excluir-se com facilidade a existência de outro fator nocivo; mas não se sabe exatamente qual das substâncias que compóem o produto é ofensiva para a saúde dos consumidores ${ }^{13}$.

Esta argumentação jurídica dividiu a doutrina penal ${ }^{14}$. De um lado estão autores que reforçam a impossibilidade de assacar qualquer responsabilidade criminal nas situações em que se desconhecem os fatores concretos prejudiciais aos objetos juridicamente tutelados ou o modo como se realiza essa ofensividade ${ }^{15}$, exigindo-se no mínimo a existência de uma lei causal que possa explicar as lesóes, sob pena de se admitir como suficiente para a demonstração do nexo causal uma mera prova indireta ou indiciária ${ }^{16}$. Entre estas vozes críticas destacam-se, em direta anotação à decisão do caso Lederspray, as vozes de INGEborg Puppe e de Erich SAmson ${ }^{17}$. De outro lado, surge o entendimento de autores que se pronunciam favoravelmente à decisão proferida pelo BGH. Desta última perspetiva considera-se que o preenchimento típico nos delitos de resultado não exige a determinação de "como" se realizou causalmente o resultado, mas unicamente "que" o autor, através da sua conduta, lhe tenha dado causa ${ }^{18}$. Entre estes autores conta-se Lothar KuHLen, que sublinha a diversa natureza e sentido da compreensão jurídica, por um lado, e científica, por outro, do conceito de causalidade. Deste modo, tendo por referência o caso Lederspray, o autor considera que "uma diferença entre a resposta jurídica afirmativa e a negação ou dúvida por parte da ciência à questão da causalidade não é, nestas circunstâncias, uma resposta fundamentada empiricamente, mas antes normativamente, isto é, nos distintos parâmetros de adequação da respetiva explicação causal" ${ }^{19}$. Por conseguinte, a determinação dos pressupostos mínimos com base nos quais uma regularidade de factos

$11 \quad$ Cf. BGHSt 37 (1992), p. 112.

12 Cf. Winfried Hassemer / Francisco Muñoz Conde, La Responsabilidad por el Producto, Tirant lo Blanch, 1995, p. 133.

13 Cf. Winfried Hassemer / Francisco Muñoz Conde, La Responsabilidad por el Producto..., op. cit., p. 133.

14 Cf. Emílio Octávio Toledo y Ubieto, «La responsabilidad penal por el producto. Un estudio general», Revista Peruana de Ciencias Penales 17 (2005), p. 487. Para uma apreciação das várias posiçóes doutrinais assumidas na Alemanha veja-se Eric Hilgendorf, «Fragen der Kausalität bei Gremienentscheidungen...», Neue Zeitschrift für Strafrecht 1994, p. 562. Também Susana Aires de Sousa, Responsabilidade Criminal pelo Produto, op. cit., p. 255 e s.

15 Neste sentido, Winfried Hassemer / Francisco Muñoz Conde, La Responsabilidad por el Producto..., op. cit., p. 137.

16 Neste sentido, Ingeborg Puppe, "Anmerkung zum Urteil des BGH v. 6-7-1990 - 2 StR 49/89» Juristische Rundschau 1992, p. 30-31.

17 Dando razão a Puppe e Samson nessa crítica, também Winfried Hassemer, / Francisco Muñoz Conde, La Responsabilidad por el Producto..., op. cit., p. 146.

18 Neste sentido, Lothar KuHLEN, «Strafhaftung bei unterlassen Rückruf gesundheitsgefährdender Produkte», Neue Zeitschrift für Strafrecht 1990, Heft 12, p. 567.

19 Neste sentido, Lothar KuHLEn, «Strafhaftung bei unterlassenem Rückruf...», op. cit., p. 567 
semelhantes pode ser considerada uma lei causal é uma questão normativa que pode encontrar uma resposta diversa no âmbito do processo penal ou em outras áreas científicas. Assim, outorga-se ao juiz "a possibilidade de responder ao 'tema da causalidade' de forma distinta ao que faria o perito científico mais competente" ${ }^{20}$. Contudo, o autor reconhece a complexidade da questão, designadamente o risco de o direito penal e as relaçóes causais afirmadas nesse contexto ficarem desacreditados em face do avanço dos conhecimentos da ciência.

Em nosso modo de ver, sem que se pretenda esboçar minimamente uma solução jurídica que extravasaria o propósito deste estudo, é essencial contextualizar o nexo de causalidade no juízo de imputação jurídico-penal e, consequentemente, nas referências axiológicas do sistema jurídico-penal. Esse passo metodológico pressupóe que a aferição da causalidade seja antes de mais enquadrada no juízo normativo de atribuição de resultados. Como já tivemos oportunidade de desenvolver em outros textos ${ }^{21}$, a atribuição de responsabilidade penal por um resultado material pressupóe em primeiro lugar a verificação de uma conduta típica, criadora de um risco juridicamente desaprovado pelas normas jurídicas e pelo dever de cuidado aferido no caso concreto. É a potencialidade lesiva da conduta que fundamenta a sua configuração típica, fazendo-a nascer juridicamente. Na senda de WolfGANG FRISCH, só uma conduta típica pode originar problemas de imputação, sendo a causalidade um facto explicativo que permite ligar um risco proibido a um resultado desvalioso, segundo um modelo de imputação causal ${ }^{22}$.

Mais do que a causalidade em si mesma - ou antes dessa causalidade -, é esta tipicidade que é desafiada de forma frontal e em primeiro lugar pelas inovaçóes proporcionadas por sistemas computacionais complexos de inteligência artificial enquanto expressão de uma inovação tecnológica ainda não regulada e cujo risco, sendo já conhecido, importa limitar na sua imprevisibilidade. $\mathrm{O}$ que distingue este produto complexo, é o risco que the é inerente, é a sua imprevisibilidade e incontrolabilidade. O risco inerente é um conceito importante em matéria de responsabilidade pelo produto porque ele constitui um parâmetro para a intervenção do direito enquanto instrumento de controlo de riscos. A grande autonomia de alguns sistemas inteligentes, associada ao contexto em que são aplicados (por exemplo, tráfego rodoviário) ou às circunstâncias em que são utilizados $(v$. g., domínio militar), impóe um dever acrescido de cuidado que deve concretizar-se em medidas jurídicas que diminuam esse risco, procurando-se dessa forma aumentar a confiança na sua segurança e modificar o grau de risco para um nível aceitável ou permitido ${ }^{23}$.

\footnotetext{
20 Cf Lothar Kuhlen, "Questiones fundamentales de la responsabilidad penal por el producto", in: Responsabilidad Penal de las Empresas y sus Órganos y Responsabilidad por el Producto, (coord. Mir Puig / Luzón Peña), Barcelona: José María Bosch Editor, 1996, p. 240.

21 Por todos, Susana Aires de Sousa, «Causalidade e imputaçáo: proposta de um modelo (o modelo da imputação causal de resultados criminalmente desvaliosos)», Estudos Comemorativos dos 20 anos da FDUP), Vol. II, Coimbra: Almedina, 2017.

22 Sobre um modelo de imputação causal, Susana AIres DE SousA, «A imputação do resultado em direito penal: a proposta de um modelo", Boletim do Instituto Brasileiro de Ciências Criminais, ano 22, no 264, novembro de 2014 , p. $2-4$.

23 Sobre este tópico, de modo desenvolvido e com adicionais referências bibliográficas, SusAnA AIRES DE SousA, "Náo fui eu, foi a máquina”: teoria do crime, responsabilidade e inteligência artificial», em curso de publicação.
} 
Deste modo, a imputação do resultado pressupõe em primeiro lugar a delimitação de uma conduta típica, revelando-se essencial, no domínio dos sistemas computacionais complexos, um mínimo de regulação e de concretização de regras de conduta. À medida que o produto se torna conhecido e os seus riscos previsíveis (e proibidos) pode justificar-se a intervenção penal, seja pela aplicação de normas existentes, seja pela criação de novas incriminaçóes. Apenas se pretende para já sublinhar que, muito embora a opacidade dos sistemas complexos confronte o direito na atribuição de responsabilidade, não é este um problema inteiramente novo. A questáo inovadora situa-se antes no plano normativo e, de modo muito particular, na determinação daquilo que se permitir em contexto de inovação tecnológica, cabendo às instâncias reguladoras afinar orientaçóes que assegurem o equilíbrio entre o risco que já se conhece e um grau de segurança capaz de nivelar aquele risco para um grau adequado a conferir a confiança necessária no produto.

\subsection{As neurociências e a categoria da culpabilidade}

Nos últimos anos, têm sido várias as questôes que as neurociências têm dirigido à ciência do direito penal. Referindo-se a esta ligação, Owen D. Jones ${ }^{24}$ sublinha que o estudo do cérebro se cruza com a ciência do direito penal desde o plano sancionatório das penas e das medidas de segurança (designadamente, no que respeita à sua eficácia, por exemplo na resposta à reabilitação de dependências ou em matéria de eficácia de intervenções farmacológicas destinadas a prevenir a reincidência), até ao plano do facto criminal, em particular no contexto da culpabilidade. A responsabilidade penal dirige uma pena a um facto censurável ao agente por uma atitude de indiferença ou de contrariedade aos comandos jurídicos. A culpabilidade estrutura assim o facto criminalmente relevante e constitui um pressuposto e limite inultrapassável da pena aplicável ao agente.

Os extraordinários desenvolvimentos alcançados nas últimas décadas pela biologia e pelo estudo da ciência do cérebro, facilitados pelas extraordinárias possibilidades tecnológicas do nosso tempo (como a imagiologia cerebral), constituíram e constituem um desafio à categoria de culpabilidade jurídico-penal, pondo em causa um dos princípios estruturantes da responsabilização penal ${ }^{25}$.

Alguns neurocientistas, como Wolf Singer, Wolfgang Prinz e Gerard Roth, com base na experimentação e no estudo clínico, sustentaram que a mente humana - os seus pensamentos, as suas emoçóes - se desenvolve de acordo com leis positivas e mediante processos causais não controláveis que se iniciam e ocorrem antes da tomada de consciência. A consciência sobre uma certa decisão aparece assim como o resultado de um processo

24 Cf. «Seven ways neuroscience aids law», Neurosciences and the Human Person: New Perspectives on Human Activities Pontifical Academy of Sciences, Scripta Varia 121, Vatican City 2013, 1-14.

25 Sobre esta questão, com maior desenvolvimento e adicionais referências bibliográficas, SUSANA AIRES DE Sousa, "Neurociências, culpa e inimputabilidade», Atas do Colóquio “Anomalia Psiquica e Direito”, organizado pelo Instituto Jurídico da Faculdade de Direito da Universidade de Coimbra, 2020 (em curso de publicação). 
causal, neurologicamente determinado (SINGER) ${ }^{26}$. Neste sentido, todas decisôes sobre o comportamento humano estão pré-determinadas e são causadas por processos causais neurológicos e complexas redes neuronais, sobre os quais não há consciência e possibilidade de controlo. Não pode deixar de se notar a semelhança entre a estrutura cerebral humana composta por redes complexas de redes neuronais e as formas mais avançadas de inteligência artificial, cuja complexidade assenta naquilo que os seus criadores e programadores designam de deep neuronal networks ${ }^{27}$.

Consequentemente, num passo subsequente e extremo, o conhecimento destas leis e mecanismos permitiria prever o comportamento humano, emergindo, a partir das neurociências, um "determinismo neurológico" 28 . Atuo desta forma por ser assim que eu sou; e sendo desta forma não posso escolher ser outro. A ideia de liberdade de escolha era, neste sentido, uma ficção. Uma construção. Esta conclusão coloca em xeque a ideia de livre arbítrio e anula a pergunta pressuposta pelo juízo de censurabilidade jurídico-penal: "podia o autor do crime atuar de modo diferente", "podia o agente agir de outra maneira?

De novo nos parece essencial contextualizar o conceito de culpabilidade no sistema jurídico-penal. A culpabilidade é um juízo de censura dirigido àquele que tem a capacidade de compreender e atuar em conformidade com a lei penal (e com os valores por ela protegidos) e, atuando, não o faz. A liberdade pressuposta pelo juízo de censurabilidade advém da capacidade para compreender os valores e os interesses protegidos pelo direito penal, cabendo ao agente, na sua livre realização, manifestar uma "atitude" - na expressão de Figueiredo DiAs - não violadora ou contrária a tais valores ${ }^{29}$.

Neste sentido, a liberdade que fundamenta um juízo de censura pressupóe apenas a "capacidade de a pessoa orientar a sua atuação pelas expectativas jurídicas" 30 pelos valores, e não o concreto mecanismo biológico que está na base da formação das nossas decisóes. A abordagem científica mostra-se, neste sentido, cirúrgica, pontual, delimitada no seu objeto de estudo ao momento de formação da consciência. Ora, o lugar da liberdade pressuposto pelo conceito de culpabilidade jurídico-penal não reside no processo fisiológico e neurológico que conduz à consciência de uma decisão e, como tal, ainda que se admita a natureza determinística deste processo, em nada interfere com a censura jurídica do agente por ter praticado um facto tido como criminalmente desvalioso.

Neste sentido, a culpabilidade não exige uma liberdade fisiológica, um multiversum de escolhas no processo biológico de formação de decisões; a natureza determinística deste

26 Cf. Wolf Singer, «Grenzen der Intuition: Determinismus oder Freiheit?» In Kiesow / Ogorek / Simitis (ed) Summa. Dieter Simon zum 70. Geburtstag, Vittorio Klostermann, Frankfurt am Main, 2005, 529-538; também Wolf Singer, Vom Gehirn zum Bewusstsein, Suhrkamp Verlag, 2006.

27 Para mais desenvolvimentos, Jасов Turner, Robot Rules, Regulating Artificial Intelligence, PalgraveMacmillan, 2019, p. 18.

28 Na expressão usada por Eduardo Demetrio Crespo, num estudo crítico a este determinismo neurológico, "Identidad y responsabilidad penal», Anuario de la Facultad de Derecho de la Universidad Autónoma de Madrid, N.o 17, 2013, p. 237-282.

29 Jorge de Figueiredo Dias, Direito Penal, Parte Geral, 3. a ed., 2019, p. 664.

30 Wolfganf Frisch, "Neurosciences and the future of culpability in criminal law», In Palma / Dias / Mendes (ed.) Emoçóes e Crime, Almedina, Coimbra, 2013, p. 147. 
processo interno, cerebral, não retira por si só a liberdade de atuar no cumprimento de normas jurídicas, que se cumpre no momento em que o agente atua e não no específico processo interno de formação da sua consciência. Em causa está, neste sentido, uma liberdade para o exterior. Ao direito não importa como se forma a consciência; mas sim se o agente é capaz de consciencializar os valores jurídicos na sua atuação ${ }^{31}$.

\section{Na teoria do processo penal}

\subsection{As neurociências e a descoberta da verdade material}

A busca da verdade constitui, na história do processo penal, um fim que sempre se mostrou difícil de alcançar: com a sua morada própria, a verdade escapa-se à capacidade de apreensão humana; e, sob a forma de aletheia desvela-se por entre contornos esbatidos ${ }^{32}$. Compreende-se assim que, ao longo da história humana, a procura da verdade - da verdade pela qual o direito se interessa - se tenha materializado num conjunto de procedimentos que, por vias indiretas ou mediatas, procuraram dar forma àquela verdade, separando-a da mentira. O escrutínio do que é dito por métodos e garantias de verdade é historicamente exemplificativo: é assim desde os grãos de arroz na antiga China ${ }^{33}$, passando pelos ordalia e juízos divinos, ou pelo juramento daquele que prestava o seu testemunho, até à concretização de técnicas mais sofisticadas como o soro da verdade, o polígrafo, as técnicas de leitura de expressóes e emoçôes ou os métodos de hipnose; também no plano jurídico se criaram formas e procedimentos de apuramento da verdade, materializados em princípios como os princípios do contraditório e da imediação. Todavia, perante as limitaçóes de todos estes métodos, técnicas e princípios, a procura pelo garante da verdade continuou.

O aperfeiçoamento dos métodos de "deteção da verdade" (ou da mentira) tornou-se uma busca constante na história do processo penal, sendo certo que, como afirma a neurocientista Martha Farah, "até aos dias de hoje nenhum método de deteção da mentira foi capaz de se apresentar como um método exato ou preciso, daí que aquela busca persista" ${ }^{4}$.

Todavia, o canto da sereia fez-se ouvir de novo no contexto das neurociências à medida que as áreas cerebrais associadas ao processo de engano e da mentira foram sendo mapeadas. A possibilidade de leitura do cérebro tornou-se uma realidade. A aplicação de novos métodos neurológicos, com particular relevância para a Imagiologia funcional cerebral por

\footnotetext{
31 Desenvolvidamente, Susana Aires De SousA, «Neurociências, culpa e inimputabilidade», op. cit. E é também esta ausência duma consciência moral que permite compreender a impossibilidade de um juízo de censurabilidade nas escolhas feitas por uma máquina autónoma, ainda que tida como "inteligente".

32 Sobre este problema, desenvolvidamente, Susana Aires de Sousa, "Neurociências e processo penal: verdade ex machina», op. cit., p. 883 e ss.

33 Cf. Martina Vicianova, «Historical techniques of Lie Detection», Europe’s Journal of Psychology, 2015, Vol. 11, p. 522 e ss. (disponível em http://ejop.psychopen.eu/article/view/919/html). Também PatowarY / BaIragi, "Lie detection: different methods with special discussion on brain fingerprinting», Medico-Legal Update, Vol. 10, N.o 2 (2010), p. 58-60.

34 Farah / Hutchinson / Phelps / Wagner, «Functional MRI-based lie detection: scientific and societal challenges», Neuroscience, vol. 15, February 2014, p. 123.
} 
ressonância magnética (fMRI) ou o Potencial evocado P300 35 , figura hoje como uma realidade processual em alguns ordenamentos jurídicos. Os novos métodos neurocientíficos direcionados à leitura da mente, aliando ciência e tecnologia, constituíram uma nova resposta que não tardaria a alcançar a investigação criminal. Entre os fins que vêm sendo atribuídos a estas novas técnicas de análise cerebral, conta-se o uso como ferramentas de leitura de informaçóes contidas no cérebro ou como instrumentos de "deteção da mentira" na informação exteriorizada por um interveniente no processo, por regra, o arguido ou o suspeito da prática do crime.

Várias são, porém, as reservas que lhe são apontadas ${ }^{36}$, quer de natureza científica e conceptual (pode a mentira enquanto fenómeno social cristalizar-se numa assinatura neuronal?), quer ainda por limites jurídicos, no plano da lei e da Constituição. A procura da verdade está desde logo limitada pela observância dos direitos fundamentais da Pessoa, exigida pelo processo penal de um Estado de Direito. No difícil equilíbrio das finalidades processuais, a admissibilidade dos métodos neurológicos como técnicas de lie detection acarreta o risco de um regresso a um processo penal apostado na descoberta da verdade em desfavor de um processo penal protetor dos direitos fundamentais da pessoa, transformada num método de obtenção de prova autoincriminatório. Em particular, o uso destas técnicas sem o consentimento do arguido $^{37}$ afeta de forma insuprível princípios fundamentais e estruturantes do processo penal, de que constitui exemplo máximo o princípio da proibição da autoincriminação. Para além dos limites processuais, admitida a leitura da mente, que restará da privacidade mental, enquanto direito fundamental substantivo?

\subsection{A IA como instrumento de previsão e de avaliação de risco}

Como já se referiu, o desenvolvimento tecnológico permitiu a criação de sistemas computacionais capazes de analisar uma enorme quantidade de dados, identificando e deter-

\footnotetext{
35 Para uma caracterização destes métodos e respetivas indicações bibliográficas, SusANA Aires DE SousA, "Neurociências e processo penal: verdade ex machina», op. cit., p. 885 e ss.

36 De modo desenvolvido, SusAna Aires DE SousA, "Neurociências e processo penal: verdade ex machina», op. cit., p. 894 e ss.

37 Um caso muito relevante neste contexto, pela discussão em torno do consentimento do arguido em se submeter à realização do exame P 300, foi o caso Ricla, julgado em Espanha. Em abril de 2012, Pilar Cebrián desapareceu da localidade onde vivia, Ricla, em Zaragoza. Havendo indícios de homicídio, o seu marido tornar-se-ia no principal suspeito, tendo sido submetido, a pedido da entidade policial responsável pela investigaçáo e por decisáo do Tribunal de Violencia sobre a Mulher, de Zaragoza, à realizaçáo deste exame neurológico, com o fim principal de se descobrir a localizaçáo do cadáver. No dia 18 de dezembro de 2013, no Hospital Universitário Miguel Servet de Zaragoza é aplicada esta técnica por uma equipa coordenada pelo médico José Ramón Valdizán Usón. Do despacho judicial que admitiu esta diligência houve recurso, com fundamento, designadamente, na violaçáo do princípio da proibiçáo da auto-incriminaçáo. A Audiencia Provincial de Zaragoza (Auto 135/2014) confirmou, ainda que com votos de vencido, a decisáo de autorizaçáo daquele exame neurológico. Porém, em novo recurso, o Tribunal Superior de Justicia de Aragon, em Julho de 2015, declarou nulo o despacho judicial que autorizava a realizaçáo daquele procedimento por violaçáo daquele princípio. Sobre este caso, Susana Aires de Sousa, Neurociências e direito penal. Nótulas à margem do caso Ricla, Instituto Jurídico da Faculdade de Direito da Universidade de Coimbra, disponível em https://www.uc.pt/fduc/ij/publicacoes/ pdfs/direitonumahora2_ebook.pdf
} 
minando padróes, realizando tarefas que ultrapassam a limitada capacidade analítica humana. As possibilidades destes sistemas vão bem além de uma mera ferramenta estatística, revelando-se como verdadeiros instrumentos de previsão, com base na análise e avaliação dos dados submetidos ao sistema. Assim, uma das características da inteligência artificial, que mais desafios convoca ao sistema de justiça penal, tanto na sua concretização prática, como na constância dos seus fundamentos essenciais, é a capacidade de formular juízos de previsão do futuro.

Em diversos momentos da realização da justiça penal, seja ainda na fase de investigação (medidas preventivas), seja na realização do julgamento (determinação da pena ou decisão sobre a aplicação de uma medida de segurança), seja na execução da sanção (concessão da liberdade condicional), o responsável pela fase judicial - órgão policial, Ministério Público, ou juiz - é instado a fazer um juízo de previsão sobre o comportamento futuro do investigado, do arguido / acusado, do condenado. Considere-se, por exemplo, um juízo sobre a previsibilidade de continuação criminosa (para efeitos de aplicação de uma prisão preventiva) ou um juízo de prognose sobre a perigosidade do arguido ou sobre a probabilidade de reincidir no cometimento de crimes, seja no contexto da substituição da pena de prisão, seja ainda para efeitos de aplicação de uma medida de segurança ou para decidir sobre a liberdade condicional. A avaliação deste risco futuro favorece o uso de sistemas de inteligência artificial, capazes de analisar uma enorme quantidade de dados e de neles encontrar padróes.

Em rigor, estes novos instrumentos de avaliação do risco (risk assessment too ${ }^{\beta}$ ) estão já a ser utilizados em ordenamentos jurídicos como o norte-americano, seja como forma de prevenção criminal, no policiamento criminal, seja como instrumento de avaliaçáo do risco criminal no contexto da determinação da sentença e da execução da pena ${ }^{39}$.

A possibilidade de prever o crime enquanto acontecimento deixa a tela cinematográfica e entra na realidade da vida sob a forma de predictive policing ${ }^{40}$, entendida como a aplicação de métodos e técnicas computacionais complexas que permitem prever os locais onde o crime acontecerá num momento futuro ${ }^{41}$. Em 2016 os títulos dos principais jornais americanos davam conta de um novo programa de inteligência artificial capaz de prever "fu-

38 Sobre a história da avaliação do risco nos Estados Unidos, veja-se Danielle KeHl / Priscilla Guo / Samuel Kessler, "Algorithms in the Criminal Justice System: Assessing the Use of Risk Assessments in Sentencing», Responsive Communities Initiative, Berkman Klein Center for Internet \& Society, Harvard Law School, 2017, p. 3 e ss. Também, na literatura portuguesa, Anabela Miranda Rodrigues, «Medida da pena de prisão - desafios da era da inteligência artificial», Revista de Legislação e Jurisprudência, Ano 149, N. 4021, 2020, p. 265 e ss.

39 Também no Reino Unido têm vindo a ser usados instrumentos preditivos do crime baseados em sistema de inteligência artificial conforme tem vindo a ser amplamente noticiado, cf. bbc.com/news/ technology-47118229

40 Um dos primeiros e mais controversos programas de previsão do crime é o PredPool, produzido por uma empresa privada e usado por vários departamentos policiais nos EUA, cf. https:/www.predpol.com/

41 Albert Meijer / Martijn Wessels, «Predictive Policing: Review of Benefits and Drawbacks», International Journal of Public Administration, Vol.42, n. ${ }^{\circ}$ 12, 2019, p. 1032. 
turos criminosos". E ainda nesse ano o Supreme Court of Wisconsin ${ }^{42}$, admitiu um software de avaliação do risco designado como COMPAS na fase de determinação da sentença, essencial para uma condenação em seis anos de prisão efetiva de Eric Loomis.

A literatura tem manifestado algumas reservas na aplicação deste algoritmos de avaliação do risco em contexto criminal, sobretudo na fase judicial, fundadas essencialmente numa ideia de lealdade e de confiança na justiça dos algoritmos (fairness), bem como nas dificuldades em perceber como funcionam estas máquinas inteligentes atendendo à sua opacidade e à falta de transparência ${ }^{43}$, o que levantará dificuldades ao exercício do contraditório e de um direito de defesa.

A estes problemas, outros se acrescentam. Alguns atingem mesmo a essência da justiça penal, com a sua possível transformação numa justiça preditiva, orientada pela pré-visáo do acontecimento criminal e pelo fim maior de construção de uma sociedade inócua e segura. Do outro lado da balança estarão, como custos, o sacrifício de direitos fundamentais (por exemplo, da liberdade daquele que é avaliado pelo sistema como sendo potencialmente perigoso) e dos princípios que estruturam um direito penal do facto e do resultado, assente na tutela subsidiária dos bens jurídicos.

\subsection{Questáo comum: o problema da admissibilidade de nova prova de natureza cien- tífica em processo penal}

O desenvolvimento técnico e científico propicia o aparecimento de novos métodos qualificados "a priori" como científicos e confronta os tribunais com o problema da sua admissibilidade. Esta é uma questão comum aos métodos neurológicos e aos meios de inteligência artificial.

No primeiro caso, já levado à apreciação de alguns tribunais, por exemplo em Espanha e nos EUA, põe-se a questão de saber se a informação recolhida por métodos neurológicos, com relevância para a comprovação dos factos que constituem o objeto do processo e do julgamento, deve ser admissível; sendo admissível, terá o valor de prova científica?

Também no que diz respeito à informação recolhida pelos sistemas de inteligência artificial se coloca uma questão semelhante, como bem nota SABINE GLESs: com a introdução destes sistemas em bens de consumo capazes de recolher e acumular informação é compreensível que se discuta a possibilidade de essas informaçóes, recolhidas por sistemas complexos computacionais, servirem em tribunal como meio de prova ${ }^{44}$. Um exemplo

\footnotetext{
42 Trata-se do caso State $v$. Loomis, sobre o qual existe imensa literatura e cuja sentença pode encontrar-se disponível em https://www.courts.ca.gov/documents/BTB24-2L-3.pdf

43 Uma apreciação destas críticas pode ver-se em ViCENT CHIAO, «Fairness, accountability and transparency: notes on algorithmic decision-making in criminal justice», International Journal of Law in Context, 15 (2019), p. 126 e ss.

44 Sobre este concreto problema, em estudo aprofundado e desenvolvido, SABINE GLESs, "AI in the courtroom: a comparative analysis of machine evidence in criminal trials", Georgetown Journal of International Law, Vol 51 (2020), p. 195 e ss.
} 
muito simples e de fácil compreensão pode vislumbrar-se em casos de acidentes rodoviários que envolvam um carro autónomo, perante o possível uso da informação recolhida por sistemas de inteligência artificial nele integrados como meio de prova. Sendo este método de informação admissível, terá esta prova natureza científica?

A questão prévia convocada por esta problemática é a de saber que requisitos deve cumprir a nova prova, pré-anunciada como científica, para que possa ser admitida, com essa qualidade, em processo. A questão póe-se sobretudo quanto ao conhecimento novo, ainda controverso pela sua novidade, e cuja compreensibilidade é dificultada pelo seu carácter complexo e altamente especializado.

Trata-se de um percurso que importa fazer e que, pelo menos no que respeita, à informação recolhida por métodos neurológicos, já começou a ser feito e discutido em tribunal. É relevante considerar a este propósito a experiência de países onde este novo tipo de técnicas tem vindo a ser requerida em processo penal. De modo particular destaca-se a jurisprudência dos tribunais americanos que muito têm discutido os parâmetros de admissibilidade da novel science em processo, fazendo recair sobre o juiz o papel de garante (gatekeeper) da prova a valorar pelos jurados. Como nos dá conta Alessandro Corda, ao juiz caberá, enquanto guardião das portas do processo, efectuar uma distinção entre boa e má ciência (junk science) de forma a impedir que esta contamine o juízo dos jurados. Isto é, de modo a evitar a valoração de provas só aparentemente científicas e que, dada essa sua aparência, possam influenciar de forma decisiva a convicção dos jurados ${ }^{45}$.

Na procura deste filtro metodológico da "novidade científica", a jurisprudência norte-americana desenvolveu critérios que procuram auxiliar o juiz, no momento de decisão, sobre a admissibilidade dos novos elementos probatórios científicos no mundo jurídicocriminal $^{46}$. Em causa estão essencialmente dois parâmetros ou critérios usados com o propósito de evitar que a má ciência possa, através de expert opinions, alcançar as decisóes dos tribunais. Em causa estão o Frye standard, estabelecido no caso Frye v. United States $^{47}$, de 1923 , em que se excluiu o testemunho pericial sobre uma forma preliminar de polígrafo como prova de inocência de um crime de homicídio, e, posteriormente, o Daubert standard ${ }^{48}$, erigido, em 1993, pelo Supremo Tribunal Americano no caso Daubert $v$. Merrel Dow Pharmaceuticals, Inc., e determinante para excluir a expert opinion favorável ao reconhecimento de novos elementos científicos sobre os efeitos teratogénicos de um medicamento (Bendectin). Representam duas formas distintas de abordagem do problema da admissibilidade da prova científica em tribunal.

\footnotetext{
45 Cf. Alessandro Corda, «Neurociencias y Derecho Penal desde el prisma de la dimensión procesal», in Neurociencia y proceso judicial (org. Michele Taruffo / Jordi Nieva Fenoll), Madrid: Marcial Pons, 2013, p.116. Também Richard GonzÁlez, "Admisibilidad, eficácia y valoración de las pruebas neurológicas...", op. cit., p. 39.

46 Um estudo pormenorizado sobre a aplicação destes critérios pela jurisprudência norte-americana, estendendo a análise à neurociência, pode ver-se em DAVID L. FAIGMAN, "Admissibility of neuroscientific expert testimony", in: A Primer on Criminal Law and Neuroscience (org. Morse/Roskies), Oxford / New York: Oxford University Press, 2013, p. 89 e ss.

47 A decisão está disponível em https://www.law.ufl.edu/_pdf/faculty/little/topic8.pdf

48 A decisão está disponível em https://supreme.justia.com/cases/federal/us/509/579/case.pdf
} 
Ao abrigo do Frye test, de natureza mais genérica, o juiz averigua se o método ou conhecimento é reconhecido e aceite pelo campo ou sector científico em que se insere, delegando à comunidade científica, em última instância, a validação da novel science.

Por sua vez, o Daubert standard, também descrito como o "gatekeeping standard" imp impóe ao juiz um papel ativo pronunciando-se em concreto sobre as bases do novo saber científico, em particular sobre os métodos e princípios seguidos na obtençáo da informação. Espera-se que o juiz se pronuncie não sobre a questão científica em si mesma, mas sobre os seus fundamentos empíricos e a metodologia usada. Com essa finalidade e de forma a decidir sobre a sua admissibilidade em processo, o juiz deve ter em conta na avaliação do novo método, técnica ou conhecimento os seguintes fatores: se se trata de um método experimental e que tenha sido concretizado não só em laboratório mas também na vida real; se foi reportado em publicaçóes com peer-review; se existe ou é determinável uma taxa de erro; se há regras, procedimentos ou protocolos que regulem a utilização desses métodos; e por fim, à semelhança do Frye standard, se se trata de um método genericamente aceite no campo científico em que se insere ${ }^{50}$.

Com base nestes critérios a $f M R I$ e a expert opinion nela fundamentada têm vindo a ser recusadas pelos tribunais americanos enquanto métodos de comprovação da veracidade das declarações prestadas em processo penal. Ainda assim, esta não é uma questão encerrada, havendo na literatura americana opiniōes que sustentam ter a prova neurológica valor suficiente para ser admitida em tribunal. Ao abrigo do princípio bad science can be good evidence, tem-se argumentado que, não obstante as fragilidades das técnicas neurobiológicas, quando comparadas com outros métodos de prova admitidos em processo, de que é exemplo máximo a prova testemunhal, apresentariam níveis superiores de credibilidade. Nas palavras de Frederick SHAuER, "the choice is between less good fMRI evidence and the even worse evidence that is not only permitted, but also forms the core of the trial" 51 .

Também em Espanha, apesar da admissibilidade da técnica encefalográfica baseada na

\footnotetext{
49 Cf. Jones / Wagner / Faigman / Raichle, "Neuroscientists in court», op. cit., p. 732 . A decisão imputa expressamente ao juiz o papel de "gatekeeper", metáfora que permaneceria na literatura sobre o tema. Transcreve-se pela sua relevância e clareza essa parte do texto: "Yet there are important differences between the quest for truth in the courtroom and the quest for truth in the laboratory. Scientific conclusions are subject to perpetual revision. Law, on the other hand, must resolve disputes finally and quickly. The scientific project is advanced by broad and wide-ranging consideration of a multitude of hypotheses, for those that are incorrect will eventually be shown to be so, and that in itself is an advance. Conjectures that are probably wrong are of little use, however, in the project of reaching a quick, final, and binding legal judgment-often of great consequence-about a particular set of events in the past. We recognize that, in practice, a gatekeeping role for the judge, no matter how flexible, inevitably on occasion will prevent the jury from learning of authentic insights and innovations. That, nevertheless, is the balance that is struck by Rules of Evidence designed not for the exhaustive search for cosmic understand but for the particularized resolution of legal disputes".

50 Para uma análise desenvolvida destes factores veja-se, David L. FAIGMAN, «Admissibility of neuroscientific expert testimony», op. cit., p. 102 e ss.

51 Frederick Schauer, "Can bad science be good evidence: lie detection, neuroscience, and the mistaken conflation of legal and scientific norms», Cornell Law Review, Vol. 95, 2009, p. 1213. Também, do mesmo autor, "Neuroscience, lie-detection, and the law, Contrary to the prevailing view, the suitability of brainbased lie-detection for courtroom or forensic use should be determined according to legal and not scientific standards», Trends in Cognitive Sciences, Vol. 14. N.o 3 (2010), p. 101-103.
} 
onda P-300 em alguns processos judiciais, surgiram fortes reservas quanto ao seu carácter científico com base nos fatores estabelecidos pelo Daubert standard ${ }^{2}$.

Numa tentativa de ensaiar uma possível delimitação conceptual do que seja prova científica, sempre se dirá que a prova científica é aquela cuja aptidão probatória advém de uma metodologia experimental, baseada em leis de tendência universal a que se reconhece validade científica e com recurso a conhecimentos e técnicas altamente especializados. $\mathrm{Na}$ sua base está o uso do método científico com fins probatórios, tendo por fim demonstrar a consistência científica de um enunciado factual que pode ter relevância no contexto de um processo penal. Muitos dos novos métodos propiciados pelo desenvolvimento tecnológico, exigindo conhecimento especiais e técnicos, carecem ainda desta aptidão probatória de base científica ${ }^{53}$. Por exemplo, os novos métodos neurológicos não superaram as dúvidas de natureza científica que lhes são dirigidas, exigindo maior certeza para que possam ultrapassar com sucesso o Daubert standard. Porém, ainda que no futuro se afirme a sua viabilidade científica, estes métodos colocam diversos problemas do ponto de vista conceptual, processual e constitucional.

No plano conceptual, importa clarificar contextos e realidades. Não pode esperar-se da neurociência a radioscopia da mentira processualmente relevante, porque esta, no seu sentido social e normativo, não pode ser captada pela "máquina". As técnicas e procedimentos de investigaçáo neurológica permitem descrever e analisar a atividade cerebral e neuronal; a valoração e o significado jurídico e social de um comportamento não pode, porém, determinar-se ex machina.

Do ponto de vista processual, no difícil equilíbrio das finalidades processuais, a admissibilidade dos métodos neurológicos como técnicas de lie detection acarreta o risco de um regresso a um processo penal apostado na descoberta da verdade em desfavor de um processo penal protetor dos direitos fundamentais da pessoa. Em particular, importa ter presente que o uso de técnicas neurológicas sem o consentimento do arguido afeta de forma insuprível princípios fundamentais e estruturantes do processo penal, de que constitui exemplo máximo o princípio da proibição da autoincriminação e o princípio da presunção de inocência.

\section{Nota conclusiva}

$\mathrm{Na}$ introdução a este texto, antecipadamente se dava conta da sua natureza fragmentária do ponto de vista teórico-crítico. Como propósito principal assumiu-se, na sua simplicidade, uma reflexão sobre como a evoluçáo do conhecimento e a introdução de tecnologias

\footnotetext{
52 Cf. M. Richard GonzÁlez, "Admisibilidad, eficacia y valoración de las pruebas neurológicas...", op. cit., p. 36 e ss., Arantza Libano Beristain, "Notas sobre la admisibilidad de la prueba neurofisiológica...", op. cit., p. 75 e ss. Em sentido contrário, mostrando-se favorável à introdução destes elementos de prova no proceso penal español, Maria Luisa Villamarín López, Neurociencia y detectión de la verdade y del engano, op. cit., p. 143 e ss.

53 Sobre estas reservas, desenvolvidamente, SusAna Aires DE SousA, "Neurociências e processo penal...", op. cit., p. 894 e ss.
} 
disruptivas - capazes de fazer, mas incapazes de serem explicadas -, é capaz de desafiar categorias e princípios que estruturam e conformam a arquitetura teórica do crime e do processo. Se alguma finalidade este texto tem é o de nos apresentar uma realidade tecnológica a que o direito não se pode furtar. Nessa resposta, a "ciência" do direito - e também do direito penal - não pode esquivar-se a opçóes fundamentais.

Ter consciência deste desafio (e da sua extensão) é de enorme relevância: só a partir desse ponto poderemos escolher de modo solidamente fundado e esclarecido o direito penal deste novo tempo. Os avanços da ciência e da técnica podem ser de enorme utilidade na procura de um direito penal mais justo; podem também ser um percurso acelerado para um direito penal securitário, capaz de sacrificar, em poucos passos, direitos fundamentais como o direito à privacidade e à intimidade ou a liberdade de expressão e de escolha. Escolher um direito penal securitário, assente nas potencialidades e possibilidades que a nova tecnologia apresenta, pode ter um custo muito elevado na restrição de direitos fundamentais ao potenciar uma resposta penal para um crime que ainda náo existe. E com isso retira-se àquele é condenado pela "máquina", a possibilidade última de não realizar esse crime. Um direito penal securitário, desligado do facto e da ofensa a bens jurídicos, centrado num direito penal do agente, tido como perigoso e de "elevado risco".

Um direito punitivo tão bem retratado pelas dúvidas de Alice em diálogo com a Rainha (do Outro Lado do Espelho ${ }^{54}$ ):

"De que tipo de coisas você se lembra melhor?", Alice se atreveu a perguntar.

"Oh, das que aconteceram daqui a duas semanas", a Rainha respondeu num tom displicente. "Por exemplo, agora", ela continuou, enrolando uma larga atadura no dedo enquanto falava, "há o Mensageiro do Rei. Está na prisão agora, sendo punido, e o julgamento não vai nem começar até quarta-feira que vem, e, é claro, o crime vem por último.”

"E se ele nunca cometer o crime?" disse Alice.

"Tanto melhor, não é?" a Rainha retrucou, prendendo a atadura em volta do dedo com um pedacinho de fita.

54 Tradução Maria Luiza X. de A. Borges, Zahar Editor, Rio de Janeiro, 2010. 